\title{
Adjunctive Reboxetine for Schizophrenia: Meta-analysis of Randomized Double-blind, Placebo-controlled Trials
}

\section{Authors}

Wei Zheng ${ }^{1}{ }^{*}$, Xian-Bin Li ${ }^{2}$, Zhan-Ming Shi ${ }^{3}{ }^{*}$, Xin-Hu Yang ${ }^{1}$, Dong-Bin Cai ${ }^{4}$, Chee H. Ng$^{5}$, Gabor S. Ungvari ${ }^{6,7}$, Wei-Jian Liu ${ }^{1}$, Yu-jie Wu', Yuan-Yuan Wang ${ }^{8}$, Yu-Ping Ning', Yu-Tao Xiang ${ }^{9}$

\section{Affiliations}

1 The Affiliated Brain Hospital of Guangzhou Medical University (Guangzhou Huiai Hospital), Guangzhou, China

2 The National Clinical Research Center for Mental Disorders \& Beijing Key Laboratory of Mental Disorders, Beijing Anding Hospital \& the Advanced Innovation Center for Human Brain Protection, Capital Medical University, Beijing, China

3 Chongqing Jiangbei Mental Health Center, Chongqing, China

4 Shenzhen Traditional Chinese Medicine Hospital, Shenzhen, China

5 Department of Psychiatry, University of Melbourne, Melbourne, Victoria, Australia

6 The University of Notre Dame Australia, Fremantle, Australia

7 Division of Psychiatry, School of Medicine, University of Western Australia, Perth, Australia

8 Faculty of Health and Life Sciences, De Montfort University, Leicester, United Kingdom

9 Unit of Psychiatry, Institute of Translational Medicine, Faculty of Health Sciences, University of Macau, Macao SAR, China

Key words reboxetine, schizophrenia, psychopathology, weight gain, meta-analysis

$\begin{array}{ll}\text { received } & 02.04 .2018 \\ \text { revised } & 25.04 .2019 \\ \text { accepted } & 29.04 .2019\end{array}$

Bibliography

DOI https://doi.org/10.1055/a-0914-3260

Published online: 17.6.2019

Pharmacopsychiatry 2020; 53: 5-13

(c) Georg Thieme Verlag KG Stuttgart · New York ISSN 0176-3679

* These authors contributed equally to the paper.

\author{
Correspondence \\ Dr. Yu-Tao Xiang \\ Faculty of Health Sciences, \\ University of Macau, \\ 3/F, Building E12, \\ Avenida da Universidade, \\ Taipa, \\ Macau SAR, \\ China \\ xyutly@gmail.com \\ Dr. Yu-Ping Ning \\ The Affiliated Brain Hospital of Guangzhou Medical \\ University (Guangzhou Huiai Hospital), \\ Guangzhou, \\ China \\ ningjeny@126.com \\ $\oplus$ \\ Supplementary information for this article is available \\ online at https://doi.org/10.1055/a-0914-3260
}

\section{ABSTRACT}

Background Results of previous studies on the safety and efficacy of adjunctive reboxetine for schizophrenia have been inconsistent.

Aim The aim of this study was to examine the efficacy and tolerability of reboxetine as an adjunct medication to antipsychotic treatment in a meta-analysis of randomized controlled trials (RCTs)

Methods Two independent investigators extracted data for a random effects meta-analysis and assessed the quality of studies using risk of bias and the Jadad scale. Weighted and standardized mean differences (WMDs/SMDs) and risk ratio (RR) $\pm 95 \%$ confidence intervals (Cls) were calculated.

Results Nine RCTs $(n=630)$ with double-blind design were identified. Reboxetine outperformed placebo in improving negative ( 9 RCTs, $n=602$, SMD: -0.47 [ $95 \% \mathrm{Cl}:-0.87,-0.07]$, $\left.p=0.02 ; I^{2}=82 \%\right)$, but not the overall, positive, and general psychopathology scores. The significant therapeutic effect on negative symptoms disappeared in the sensitivity analysis after removing an outlying study and in 50\% (6/12) of the subgroup analyses. Reboxetine outperformed placebo in reducing weight (3 RCTs, $n=186$, WMD: $-3.83 \mathrm{~kg}, \mathrm{p}=0.04 ; \mathrm{I}^{2}=92 \%$ ) and body mass index (WMD: $-2.23 \mathrm{~kg} / \mathrm{m}^{2}, \mathrm{p}=0.04 ; \mathrm{I}^{2}=95 \%$ ). Reboxetine 
caused dry mouth but was associated with less weight gain overall and weight gain of $\geq 7 \%$ of the initial weight. All-cause discontinuation and other adverse events were similar between reboxetine and placebo.
Conclusion Adjunctive reboxetine could be useful for attenuating antipsychotic-induced weight gain, but it was not effective in treating psychopathology including negative symptoms in schizophrenia.

\section{Introduction}

Schizophrenia is a severe and chronic psychiatric disorder. Nearly $50 \%$ of schizophrenia patients fail to respond to antipsychotic (AP) monotherapy, particularly in terms of negative symptoms [1-3]. Augmentation strategies are commonly used to enhance AP efficacy and to reduce adverse drug reactions (ADRs) induced by APs [2, 4-6].

Most negative symptoms (e. g., anhedonia and social withdrawal) are likely to be intrinsic to schizophrenia [7] and associated with neurocognitive deficits [8] including impaired attention, memory, and executive functions [9]. Certain augmentation strategies appear to be effective to improve the negative symptoms of schizophrenia; for example, adjunctive antidepressants have a moderate effect size for negative symptoms [7, 10].

In the past two decades, weight gain induced by APs has attracted increased attention [11-16]. Weight gain is associated with poor treatment adherence and quality of life, higher rate of medical comorbidity particularly cardiovascular diseases, diabetes mellitus, and osteoarthritis and mortality $[12,13,17-21]$. Reboxetine, a norepinephrine reuptake inhibitor, is an antidepressant and antianxiety drug $[18,22]$. According to a recent meta-analysis, as an antidepressant, reboxetine is ineffective and causes side effects [23]; however, in another network meta-analysis, reboxetine appeared to have antidepressant effect in major depression [24]. Some trials have found that reboxetine is safe and efficacious in treating negative symptoms of schizophrenia [25-28] and AP-induced weight gain in some $[18,22,27]$ but not all $[29,30]$ randomized controlled trials (RCTs).

The efficacy of reboxetine in treating negative symptoms and/ or reducing AP-induced weight gain in schizophrenia have been examined in meta-analyses [10,12,31-34]. Common limitations of these meta-analyses include the small number of included studies, resulting in insufficient power. For example, 3 meta-analyses $[12,33,34]$, each with 2 RCTs $(n=85)[18,22]$, found that reboxetine was superior to placebo in reducing AP-induced weight gain. Another meta-analysis [31] included 9 RCTs, but one of them was an open-label study [35], the inclusion of which violated standard recommendations [36]. In addition, non-English databases were not searched for relevant RCTs [26].

The aim of this study was to obtain more robust evidence regarding the efficacy and safety of adjunctive reboxetine added to APs. To this end, a comprehensive meta-analysis was conducted involving all RCTs on reboxetine added to all types of APs in treating schizophrenia including also recent RCTs published in Chinese, which were not included in previous meta-analyses.
Methods

\section{Types of studies}

According to the PICOS acronym, the selection criteria were as follows: participants $(P)$, patients with schizophrenia diagnosed according to any criteria; intervention (I), reboxetine plus APs; comparison (C), APs plus placebo; outcomes (O), efficacy and safety of adjunctive reboxetine with meta-analyzable data; study design (S), randomized, double-blind, placebo-controlled trials. A methodically sound RCT [37] was excluded because patients were selected from the combined sample of 2 other RCTs [18, 22].

\section{Outcome measures}

Clinical outcomes were recorded based on intent-to-treat (ITT) analysis, if provided. The co-primary outcome measures were the change of negative symptoms assessed with the Positive and Negative Syndrome Scale (PANSS) [38] or the Brief Psychiatric Rating Scale (BPRS) [39] or the total scores of the Scale for the Assessment of Negative Symptoms (SANS) [40] and body weight ( $\mathrm{kg}$ ). Key secondary outcomes were the changes of total, positive, and general psychopathology scores of the PANSS or BPRS or the total scores of the Scale for the Assessment of Positive Symptoms (SAPS) [41], body mass index (BMI, $\mathrm{kg} / \mathrm{m}^{2}$ ), cognitive functions, ADRs, and allcause discontinuation rate.

\section{Study selection}

The PubMed, PsycINFO, EMBASE, the Cochrane Library, Chinese Journal Net, WanFang, and the China Biology Medicine databases were independently and systematically searched by 2 reviewers from their inception until November 3, 2016. The keywords for the search were (reboxetine OR Edronax) AND (schizophrenic disorder OR disorder, schizophrenic OR schizophrenic disorders OR schizophrenia OR dementia praecox). Reference lists from review articles $[10,12,31-34]$ were hand-searched for additional studies. First/ corresponding authors were contacted for missing information, whenever necessary.

\section{Data extraction}

Data were independently identified, checked, extracted, and analyzed by 2 reviewers. Inconsistencies were resolved by consensus involving a third reviewer. If data from the same study were reported in more than 1 RCT, only the RCT with complete data was included in the analyses.

\section{Statistical methods}

According to the guidelines of the Preferred Reporting Items for Systematic Reviews and Meta-Analyses (PRISMA) statement [42], data 
were summarized statistically using the Review Manager version 5.3 (http://www.cochrane.org) if they were available and sufficiently similar. A random effects model was used in all cases [43]. For the metaanalytic pooling of continuous outcomes, weighted or standardized mean differences (WMDs or SMDs) with their $95 \%$ confidence intervals (Cls) are reported. Summary statistics of dichotomous outcomes are presented as risk ratios (RRs) $\pm 95 \% \mathrm{Cls}$. When RRs were significant, number-needed-to-harm (NNH) was calculated by dividing 1 by the risk difference. Whenever both change score and endpoint values of a continuous outcome were available, change scores were preferred. Missing standard deviation (SD) was replaced by the average SD of other RCTs following the suggestion of Leucht et al. [36]. In cases of $\mathrm{I}^{2}>50 \%$ for co-primary outcomes, reasons were sought to explain the heterogeneity by conducting a sensitivity analysis (i.e., removing 1 outlier [SMD $\leq-1.3$ ] study) [27]. In addition, the following 6 subgroup analyses were performed to identify the reasons for the heterogeneity of significance: (1) Chinese versus non-Chinese studies; (2) clozapine vs. other APs; (3) trial duration (weeks): $\geq 12$ vs. $<12$ (mean splitting method for trial duration); (4) age: $\geq 38.0$ vs. $<38.0$ years (mean splitting method for age); (5) male predominance ( $\geq 60 \%$ ) vs. no sex predominance; (6) study quality: Jadad score $\geq 3$ vs. $<3$. The above subgroup analyses were repeated after leaving out 1 outlying study [27]. Funnel plots and Egger's test [44] were used to judge publication bias. All analyses were 2 tailed, with alpha set at 0.05 .

\section{Assessment of the studies}

Cochrane risk of bias [45] was employed to assess the methodological quality of RCTs ( $>$ Fig. 1S). The Grading of Recommendations, Assessment, Development, and Evaluation (GRADE) system $[46,47]$ was performed to estimate the recommendation for outcome measures of adjunctive reboxetine for schizophrenia. Following the methodology of other studies [31,48], the Jadad scale (range: $0-5$ ) assessed the quality of included studies ( $\triangleright$ Table 1 ) [49]. The Jadad total score of $\geq 3$ indicated "high quality" [50].

\section{Results}

\section{Results of the search}

The original search from the above databases yielded 339 electronic records and 1 trial retrieved by hand-search ( $\triangleright$ Fig. 1). By the end of screening all papers, 9 RCTs [18, 22, 25-30, 51] published in English (6 RCTs) [18, 22, 28-30, 51] and Chinese (3 RCTs, (• Table 1S) [25-27] were eligible and analyzed.

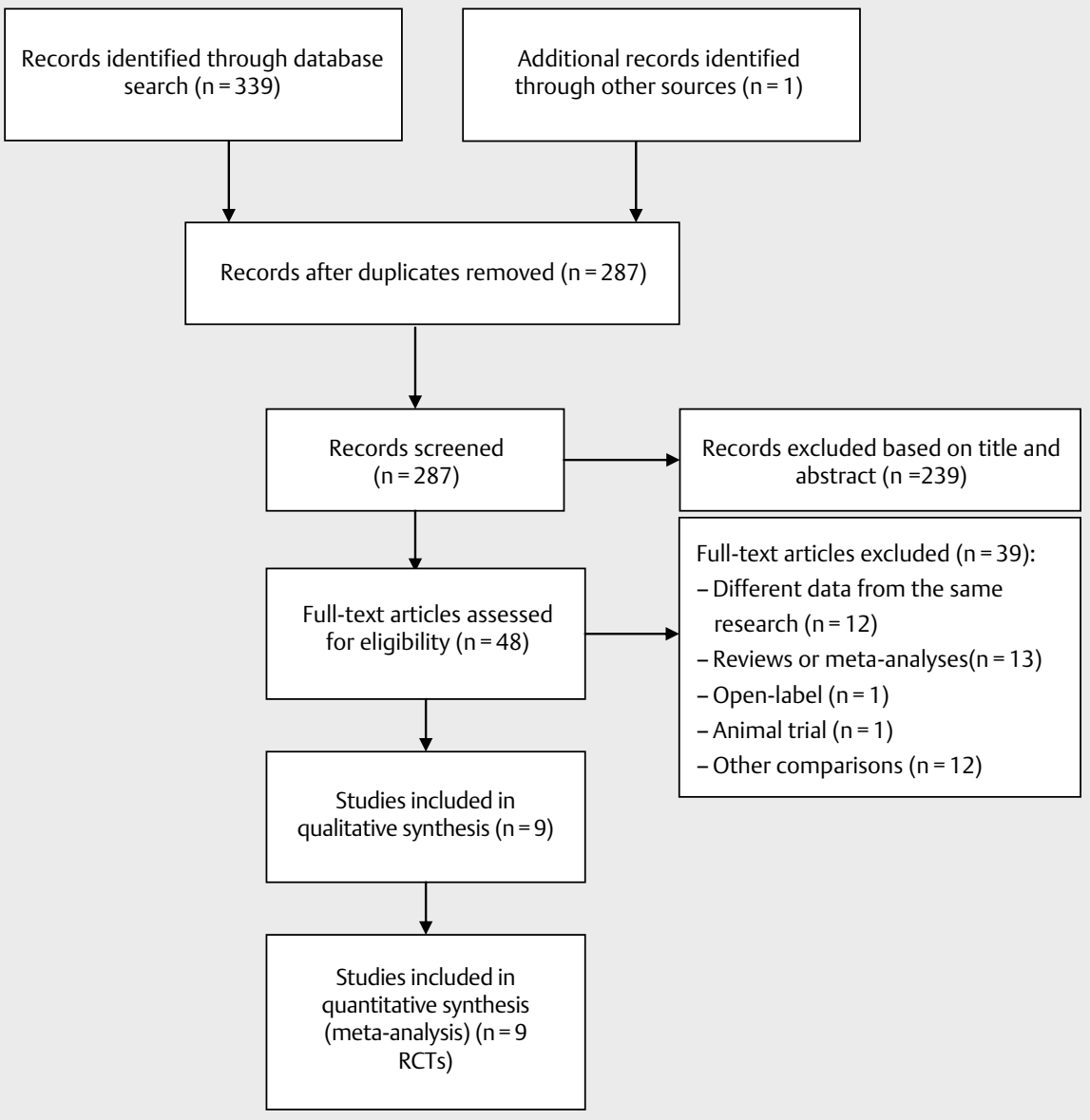

- Fig. 1 PRISMA flow diagram. 


\section{Study characteristics}

All 9 RCTs ( $n=630)$ were double-blind and $4(44.4 \%, n=211)$ used ITT analyses. The mean study duration was $11.8 \pm 7.6$ (range: $4-24$, median: 12.0 ) weeks ( $\triangleright$ Table 1$)$. Three RCTs were conducted in China ( $n=363), 2$ in Israel ( $n=85)$, and 1 each in Iran $(n=50)$, South Africa $(n=30)$, Germany $(n=35)$, and Spain $(n=67)$.

\section{Patient characteristics}

The mean age of the 630 patients was $38.0 \pm 6$.9 years (range: 29.9 50.4, median: 40.4 years); males accounted for $79.5 \pm 18.9 \%$ (range: $50.8-100$, median: 73.1 ) of the sample. The mean illness duration was $10.6 \pm 9.4$ (range: $0.4-27.2$, median: 8.5 ) years (8 RCTs with available data) ( $\triangleright$ Table 1$)$. Six RCTs were conducted in inpatients $(n=393), 1$ RCT involved both in- and outpatients $(n=135)$, and the type of patients in 2 RCTs $(n=102)$ was unspecified.

\section{Treatment characteristics}

Reboxetine dose was $6.2 \pm 1.8 \mathrm{mg} /$ day (range: $4.0-8.0$, median: $6.0 \mathrm{mg} /$ day). Baseline APs included olanzapine ( $2 \mathrm{RCTs}, \mathrm{n}=85$ ), clozapine ( 2 RCTs, $n=228$ ), haloperidol ( 3 RCTs, $n=215$ ), and multiple APs (2 RCT, $n=102)$ ( Table 1 ).

\section{Quality assessment}

While 8 RCTs (88.9\%) [18, 22, 25-29, 51] were rated as low risk regarding attrition bias, 4 RCTs $[18,22,29,30]$ described an adequate method of random sequence generation and 2 RCTs [29, 30] were rated as low risk regarding the allocation concealment methods ( $\vee$ Fig. 1S). In addition, 5 RCTs (63\%) [18, 22, 28, 29, 51] were rated as low risk for selective report bias. According to the GRADE approach, the quality of evidence for 10 outcomes ranged from “low"(20\%) via "moderate" (40\%) to "high" (40\%) ( Table 2S). The mean score of the Jadad scale was 3.6 \pm 1.1 (range: $2-5$; median: 3.0 ); 8 RCTs (88.9\%) were classified as high quality ( $\triangleright$ Table 1 ).

\section{Psychotic symptoms}

Meta-analysis of negative symptoms (PANSS [6 RCTs] and SANS [3 RCTs]) showed that adjunctive reboxetine was superior to placebo (9 RCTs, $n=602$, SMD: -0.47 [95\% Cl: $-0.87,-0.07$ ], $p=0.02 ; I^{2}=82 \%$, $>$ Fig. 2 ). The significance (SMD: $-0.36[95 \%$ $\mathrm{Cl}:-0.77,0.05], \mathrm{p}=0.09 ; \mathrm{I}^{2}=79 \%$ ) disappeared after 1 outlying (SMD $\leq-1.3$ ) study [27] was removed. In subgroup analyses, the significance also disappeared in 6 out of the 12 subgroups ( $\triangleright$ Table 2 ). The superiority of reboxetine disappeared in non-Chinese studies $(p=0.59)$, with APs other than clozapine $(p=0.27)$, trials lasting less than 12 weeks $(p=0.37)$, male predominance ( $\geq 60 \%$ ) $(p=0.10)$, mean age younger than 38.0 years $(p=0.54)$, and having a Jadad score more than $3(p=0.10)$. (Table $2 S$ ) presents subgroup analyses after leaving out 1 outlying study [27] and found that significance disappeared in 7 out of the 12 subgroups. The superiority of reboxetine disappeared in non-Chinese studies $(p=0.59)$, APs other than clozapine $(p=0.27)$, trials lasting less than 12 weeks $(p=0.37)$, male predominance $(\geq 60 \%)(p=0.26)$, mean age younger $(p=0.54)$ or older than 38.0 years $(p=0.11)$, and having a Jadad score more than $3(p=0.26)$.

No group difference was found in change of overall psychopathology measured with the PANSS (6 RCTs) ( $n=473$, SMD: -0.50
[95\% Cl: - 1.05, 0.06], $p=0.08 ; \mathrm{I}^{2}=88 \%$; Fig. 2), positive symptoms (PANSS [6 RCTs] and SAPS [3 RCTs]) ( $n=602$, SMD: -0.00 [95\% Cl: $-0.16,0.16$ ], $p=0.98 ; I^{2}=0 \%$; Fig. 2 ) and PANSS general psychopathology score (5 RCTs) ( $n=438$, SMD: $-0.46[95 \%$ $\mathrm{Cl}:-0.97,0.05], \mathrm{p}=0.08 ; \mathrm{I}^{2}=85 \%$, > Fig. 2 ).

\section{Weight change}

Compared to placebo, reboxetine caused significant weight (3 RCTs, $\mathrm{n}=186$, WMD: $-3.83 \mathrm{~kg}[95 \% \mathrm{Cl}:-7.40,-0.26], \mathrm{p}=0.04 ; \mathrm{I}^{2}=92 \%$; -Fig. 3) and BMI reduction ( 3 RCTs, $n=186$, WMD: $-2.23 \mathrm{~kg} / \mathrm{m}^{2}$ [95\% Cl: $-4.35,-0.12$ ], $p=0.04 ; \mathrm{I}^{2}=95 \%$, $>$ Fig. 3 ). The results concerning weight (WMD: $-1.90 \mathrm{~kg}[95 \% \mathrm{Cl}:-3.07,-0.72], \mathrm{p}=0.002$; $\left.\mathrm{I}^{2}=0 \%\right)$ was consistent even after 1 outlier $(\mathrm{SMD}<-1.0)$ study [27] was removed.

\section{Cognitive functions}

Only 2 RCTs [26, 27] assessed cognitive functions. One study [26] found reboxetine superior to placebo in memory quotient, recognition, and associative learning assessed by the Wechsler Memory Scale-Revised, Chinese version. The other study [27] found reboxetine outperformed placebo in attention, immediate memory, and delayed memory assessed with the Repeatable Battery for the Assessment of Neuropsychological Status. Because of the different scales used, meta-analysis of cognitive functions was not possible.

\section{Discontinuation rate and ADRs}

All-cause discontinuations were similar between reboxetine and placebo (8 RCTs, $n=580$, RR: 1.05 [95\% Cl: 0.71, 1.56], $p=0.81$, $\mathrm{I}^{2}=0 \%$; ( Fig. 2S). Regarding ADRs, reboxetine caused more frequent dry mouth ( $p=0.04, \mathrm{NNH}=14,95 \% \mathrm{Cl}$ : 7-50; - Fig. 3S) but was associated with less weight gain overall $(\mathrm{p}=0.01, \mathrm{NNH}=7,95 \%$ $\mathrm{Cl}: 4-50)$ and weight gain of $\geq 7 \%$ of the initial weight $(p=0.006$, $\mathrm{NNH}=3$, $95 \% \mathrm{Cl}$ : 2-8; - Fig. 3S). Meta-analyses of akathisia, dizziness, insomnia, tachycardia, constipation, and nausea/vomiting showed no significant differences between reboxetine and placebo ( $p=0.21-0.82$; Fig. 3S).

\section{Publication bias}

Since a minimum of 10 RCTs are needed to conduct funnel plot or Egger's test [52], publication bias was not assessed for negative symptoms (9 RCTs) and weight change (3 RCTs).

\section{Discussion}

This meta-analysis found that reboxetine was not consistently effective in treating negative symptoms because the significant improvement was driven by an outlying study [27]. This result is consistent with previous findings [10,32]. In this meta-analysis, adjunctive reboxetine was effective in weight reduction in the treatment of schizophrenia. Compared with Helfer et al.'s metaanalysis [32] of 5 RCTs [18, 22, 29, 30, 51], 4 additional RCTs [25-28] were included in this study, generating larger power and allowing more comprehensive analyses. A recent meta-analysis [31] concluded that reboxetine may improve negative symptoms, but the evidence presented was of a very low quality, probably due to the inclusion of an open-label study [35]. In the present meta-analysis, a significant effect of reboxetine on negative symptoms was only 


\begin{tabular}{|c|c|c|c|c|c|c|c|c|c|c|}
\hline 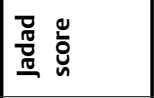 & $m$ & $m$ & 乞n & in & $m$ & $m$ & $\sim$ & in & $m$ & \\
\hline 产产 & $\sim$ & $\sim$ & in & เn & $\nabla$ & $\nabla$ & $\sim$ & in & $m$ & 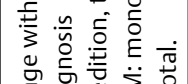 \\
\hline 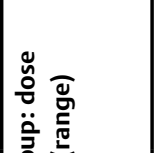 & 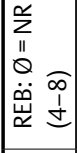 & 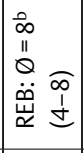 & 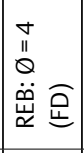 & 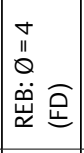 & \begin{tabular}{|l|} 
\\
$\ddot{\theta}$ \\
$\ddot{\theta}$ \\
$\ddot{\ddot{u}}$ \\
$\ddot{\alpha}$
\end{tabular} & 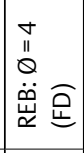 & 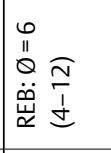 & 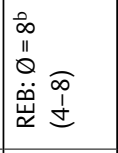 & 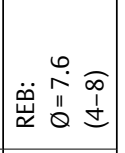 & 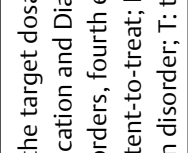 \\
\hline 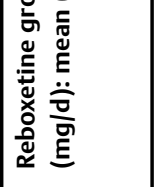 & 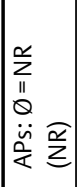 & 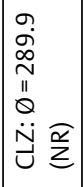 & 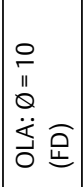 & 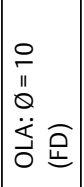 & 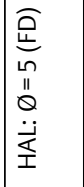 & 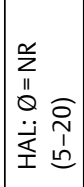 & 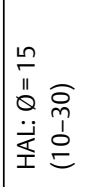 & 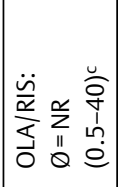 & 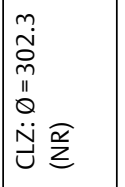 & 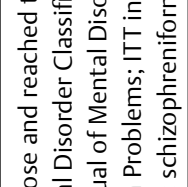 \\
\hline 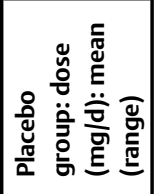 & 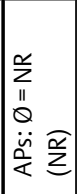 & 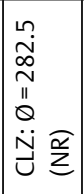 & 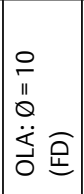 & 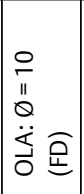 & 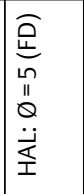 & 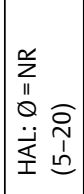 & 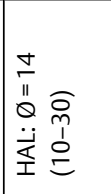 & 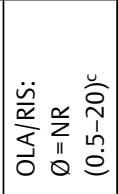 & 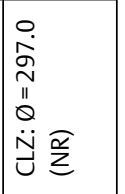 & 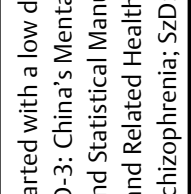 \\
\hline 节泀 & 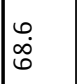 & 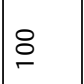 & 苞 & $\stackrel{+}{+}$ & $\begin{array}{l}m \\
\tilde{n}\end{array}$ & 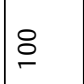 & 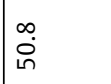 & $\bar{r}$ & $\stackrel{8}{\circ}$ & 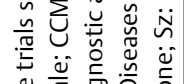 \\
\hline 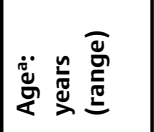 & 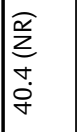 & 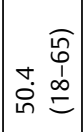 & \begin{tabular}{ll|} 
& $\widehat{a}$ \\
& $\stackrel{+}{1}$ \\
$\infty$ & $\vdots$ \\
$\dot{\rho}$ & $\stackrel{\sigma}{=}$
\end{tabular} & 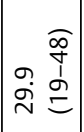 & 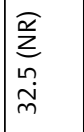 & 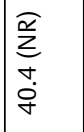 & 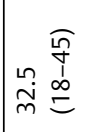 & 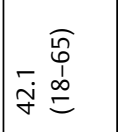 & 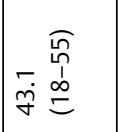 & 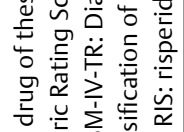 \\
\hline 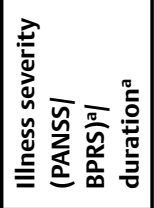 & 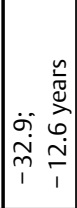 & 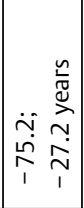 & 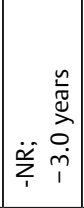 & 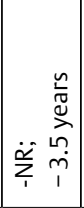 & 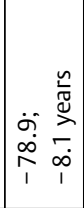 & 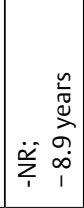 & 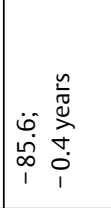 & 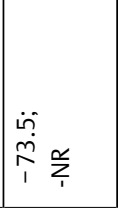 & 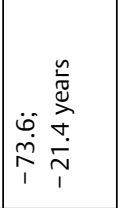 & 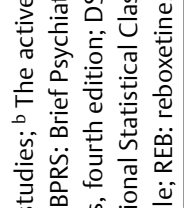 \\
\hline 悹 & $\sum_{\substack{1 \\
0}}^{\geq}$ & $\sum_{\dot{U}}^{m}$ & $\sum_{\substack{1 \\
0}}^{\geq}$ & $\sum_{\substack{1 \\
\Delta}}^{\geq}$ & $\sum_{n}^{1}$ & 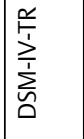 & $\sum_{\substack{1 \\
0}}^{\geq}$ & $\sum_{\substack{1 \\
0}}^{\geq}$ & $\begin{array}{l}0 \\
1 \\
1 \\
\underline{0}\end{array}$ & 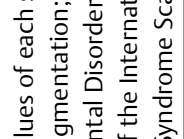 \\
\hline 嵩 & 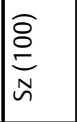 & 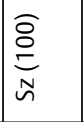 & $\begin{array}{l}\stackrel{O}{O} \\
\stackrel{D}{N} \\
\text { n }\end{array}$ & 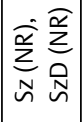 & 命 & $\begin{array}{l}\stackrel{\Xi}{O} \\
\stackrel{N}{N} \\
\sim\end{array}$ & $\begin{array}{l}\stackrel{O}{O} \\
\stackrel{\Xi}{N} \\
\sim\end{array}$ & $\begin{array}{l}\stackrel{O}{O} \\
\stackrel{D}{N} \\
\sim\end{array}$ & 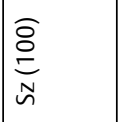 & 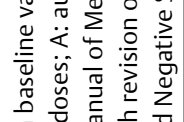 \\
\hline 异 & $\frac{o}{z}$ & 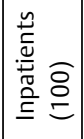 & 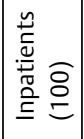 & 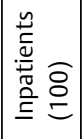 & 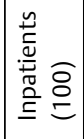 & 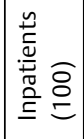 & 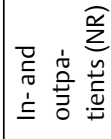 & $\frac{a}{z}$ & 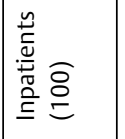 & 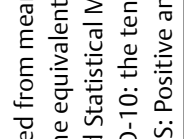 \\
\hline 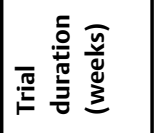 & $\nabla$ & $\simeq$ & 0 & 0 & 0 & $\simeq$ & $\simeq$ & $\stackrel{d}{\sim}$ & $\stackrel{\sim}{\sim}$ & 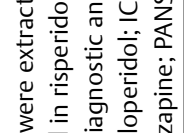 \\
\hline 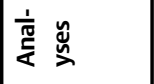 & $E$ & ๖ & ૪ & E & $\frac{o}{z}$ & E & ð & E & ○ & $\frac{0}{2}$ \\
\hline$\frac{\dot{1}}{\underline{\underline{\underline{L}}}}$. & ๑ొ & ๑ & $\stackrel{\text { ๑ }}{ }$ & $\stackrel{\circ}{\circ}$ & $\stackrel{\sim}{\circ}$ & $\stackrel{\sim}{\circ}$ & ฉ̊ & $\stackrel{\circ}{\circ}$ & $\stackrel{\circ}{\circ}$ & \\
\hline 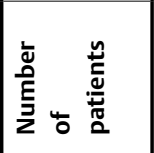 & 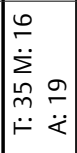 & 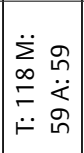 & 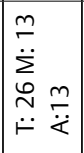 & 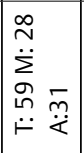 & 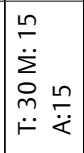 & 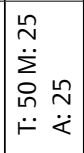 & $\begin{array}{ll}\ddot{\sum} & 0 \\
\mu & 0 \\
m & \ddot{x} \\
\ddot{\bullet} & 0\end{array}$ & 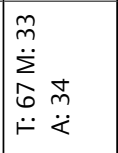 & 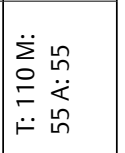 & 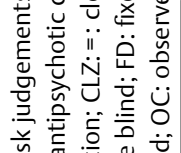 \\
\hline 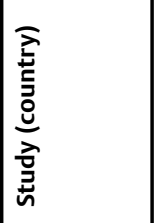 & 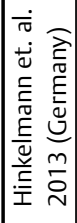 & 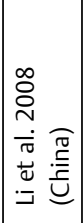 & 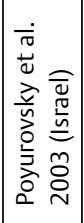 & 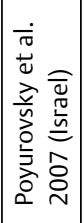 & 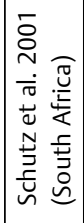 & 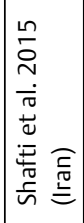 & 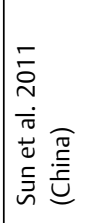 & 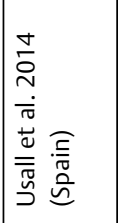 & 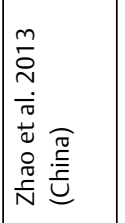 & 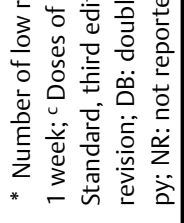 \\
\hline
\end{tabular}




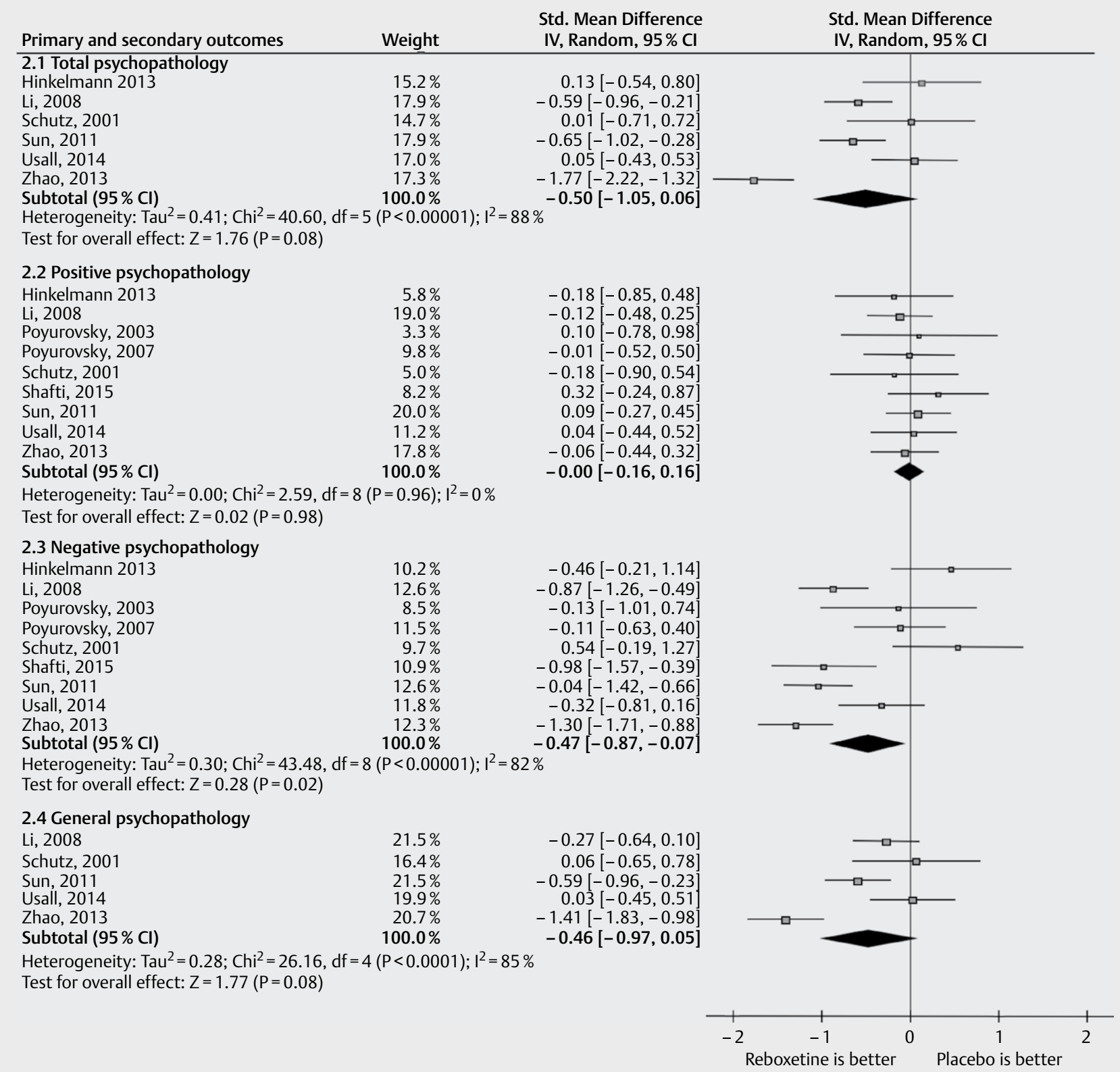

- Fig. 2 Reboxetine for schizophrenia. Forest plot for clinical efficacy assessed with the PANSS, BPRS, SAPS, or SANS.

found in the Sun et al.'s study (Jadad score $<3, p<0.00001$ ) but not in the remaining 7 studies (Jadad score $\geq 3, p=0.26$ ) after leaving out 1 outlying study [27].

Reboxetine administered for 12 weeks reduced weight by a mean of $3.83 \mathrm{~kg}$ by reducing appetite and increasing energy expenditure [53]. In a recent RCT of 40 schizophrenia patients, a reboxetine-betahistine combination caused significant weight loss compared to placebo (4.77 vs. $2.02 \mathrm{~kg}$ ) [54]. In a systematic review of 40 trials, metformin achieved the greatest weight loss $(3.17 \mathrm{~kg}$; $95 \% \mathrm{Cl}:-4.44,-1.90)$ compared to topiramate, sibutramine, aripiprazole, and reboxetine [17]. In another meta-analysis [34] topiramate, aripiprazole, and sibutramine were more effective than reboxetine to induce weight loss. To date, there has been no head- to-head study or meta-analysis published that directly compared reboxetine and metformin on weight loss.

Adjunctive reboxetine appeared to be safe and well-tolerated. Reboxetine caused more frequent dry mouth $(\mathrm{NNH}=14)$ but less weight gain ( $\mathrm{NNH}=7$ ) and weight gain of $\geq 7 \%$ of the initial weight $(\mathrm{NNH}=3)$. Other ADRs and discontinuation were similar between reboxetine and placebo.

Several studies examined the association between AP-induced weight gain and treatment response in schizophrenia. Treatment response was positively associated with weight gain induced by olanzapine or clozapine [19] and olanzapine and haloperidol [55]. However, only $33 \%$ (3/9) of the RCTs in the present meta-analysis explored the effect of reboxetine on AP-induced weight gain, without 
- Table 2 Subgroup analysis of the associations between moderating variables and change in negative symptoms.

\begin{tabular}{|c|c|c|c|c|c|}
\hline Variables & n (subjects) & SMDs (95\% Cl) & $I^{2}(\%)$ & $\begin{array}{l}\text { p-value for } \\
\text { each subgroup }\end{array}$ & $\begin{array}{l}\text { p-value across } \\
\text { subgroups }\end{array}$ \\
\hline 1. Chinese & $3(341)$ & $-1.06(-1.29,-0.82)$ & 7 & $<0.00001$ & \multirow[t]{2}{*}{0.0002} \\
\hline Non-Chinese & $6(261)$ & $-0.12(-0.55,0.31)$ & 66 & 0.59 & \\
\hline 2. Antipsychotic class: Clozapine & $2(221)$ & $-1.08(-1.49,-0.66)$ & 53 & $<0.00001$ & \multirow[t]{2}{*}{0.01} \\
\hline Other than Clozapine & $7(381)$ & $-0.27(-0.74,0.21)$ & 79 & 0.27 & \\
\hline 3. Trial duration (weeks) ${ }^{\mathrm{a}}: \geq 12$ & $5(458)$ & $-0.91(-1.22,-0.61)$ & 58 & $<0.00001$ & \multirow[t]{2}{*}{$<0.00001$} \\
\hline$<12$ & $4(144)$ & $0.16(-0.19,0.51)$ & 10 & 0.37 & \\
\hline 4. Age (years) $: \geq 38.0$ & $5(373)$ & $-0.64(-1.16,-0.11)$ & 83 & 0.02 & \multirow[t]{2}{*}{0.37} \\
\hline$<38.0$ & $4(229)$ & $-0.23(-0.95,0.49)$ & 84 & 0.54 & \\
\hline 5. Male predominance ( $\geq 60 \%)$ & $8(482)$ & $-0.38(-0.84,0.07)$ & 82 & 0.1 & \multirow[t]{2}{*}{0.03} \\
\hline No sex predominance & $1(120)$ & $-1.04(-1.42,-0.66)$ & $\mathrm{N} / \mathrm{A}$ & $<0.00001$ & \\
\hline 6. Study quality: Jadad score $\geq 3$ & $8(482)$ & $-0.38(-0.84,0.07)$ & 82 & 0.1 & \multirow[t]{2}{*}{0.03} \\
\hline Jadad score $<3$ & $1(120)$ & $-1.04(-1.42,-0.66)$ & 0 & $<0.00001$ & \\
\hline
\end{tabular}

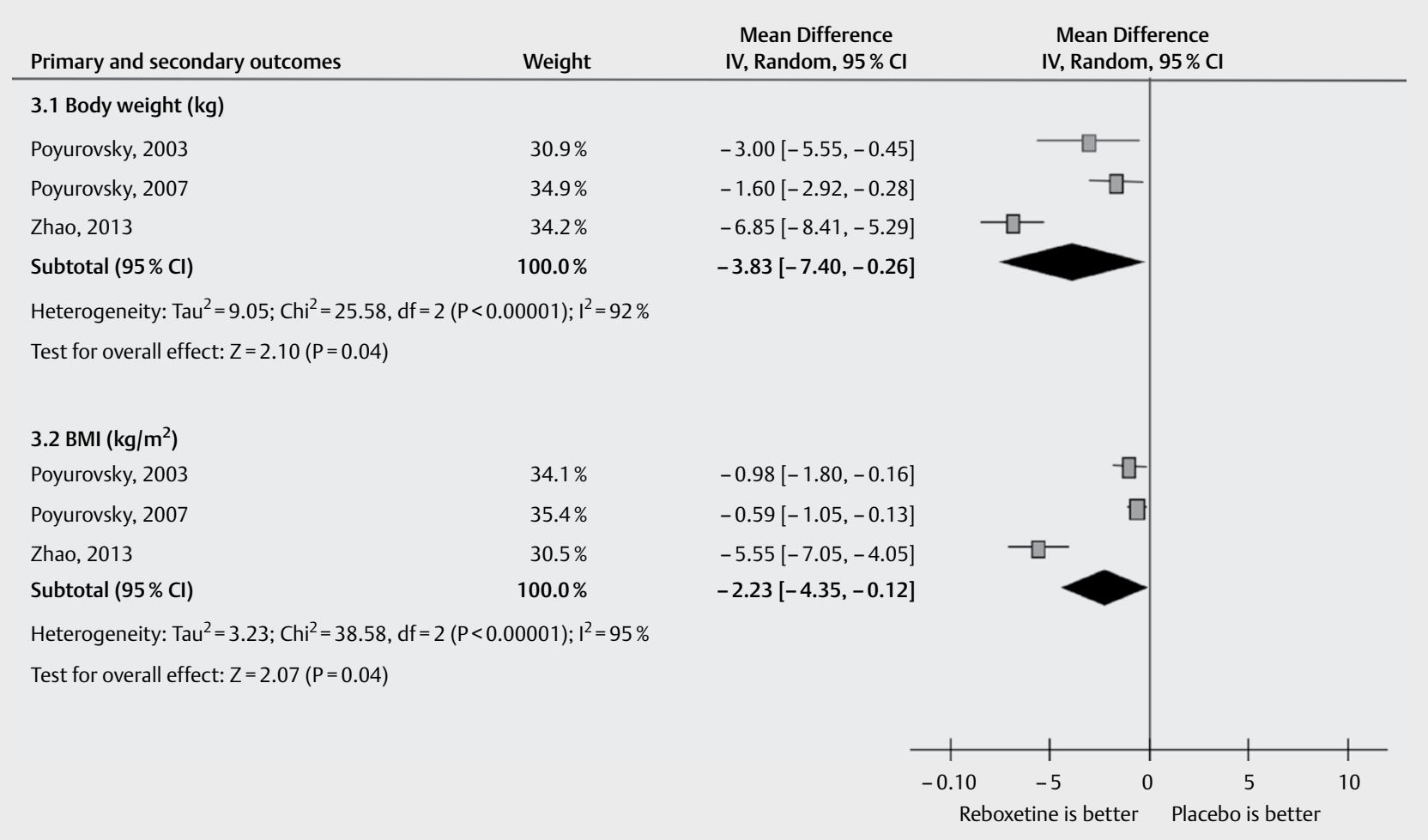

Fig. 3 Reboxetine for schizophrenia. Forest plot for the change of body weight and BMI.

investigating the association between reboxetine and negative symptoms; thus, the association between AP-induced weight gain and negative symptoms could not be assessed in this meta-analysis.

Three previous meta-analyses [12,33,34] of 2 RCTs [18, 22] found similar advantage of adjunctive reboxetine for attenuating weight gain in schizophrenia, but they did not analyze its effects on psychotic symptoms. The current meta-analysis included additional 7 RCTs, allowing more robust and sophisticated analyses, including risk of bias, Jadad scale, GRADE approach, and sensitivity analysis.
There are several limitations of this meta-analysis. First, although all included RCTs were rated as high-quality trials according to the Cochrane risk of bias and the Jadad scale, all 9 RCTs providing the data of co-primary outcomes had relatively small sample size (26135), which precluded the assessment of publication bias. Second, meta-analyzable results for body weight $\left(I^{2}=92 \%\right)$ were heterogeneous, although the statistical significance remained $\left(I^{2}=0 \%\right)$ after removing an outlying study from the analysis. Third, reboxetine doses varied across the 9 studies $(4.0-8.0 \mathrm{mg} /$ day); therefore, the 
dose-response effects of reboxetine in reducing AP-induced weight gain could not be examined. Fourth, cognitive functions were assessed only in 2 trials $[26,27]$ with conflicting conclusions. The cognitive aspects of reboxetine treatment warrant further investigations. Fifth, all studies had relatively short treatment duration (4-24 weeks); thus, reboxetine's long-term effects on body weight need further studies. Finally, metabolic indices associated with body weight, such as lipid profile, insulin resistance, and leptin could not be analyzed as they were not recorded in the studies.

In conclusion, in this meta-analysis, reboxetine appeared to attenuate AP-induced weight gain in patients with schizophrenia, but it was not consistently effective in treating negative symptoms of schizophrenia. The therapeutic effects of reboxetine on negative symptoms remained doubtful in this meta-analysis as it was driven by an outlying study. In the outlying study [27], schizophrenia patients with metabolic syndrome were recruited. Therefore, the effect of reboxetine on negative symptoms needs to be probably replicated. In addition, high-quality RCTs are warranted to demonstrate reboxetine's long-term safety and efficacy, particularly on cognitive functions.

\section{Role of the Funding Source}

The study was supported by the University of Macau (SRG201400019-FHS; MYRG2015-00230-FHS; MYRG2016-00005-FHS), the National Natural Science Foundation of China (81601169), the Beijing Municipal Administration of Hospitals Clinical Medicine Development of Special Funding Support (ZYLX201807, XLMX201807), Capital's Funds for Health Improvement and Research (2018-22123), and the Major Science and Technology Award of the Science and Technology Department of Guangdong Province (2016B0 10108003).

\section{Contributors}

WZ and XHY selected studies and conducted statistical analysis. $\mathrm{XHY}$ and DBC extracted the data. YTX reviewed all the data and helped mediate disagreements. WZ, XBL, and ZMS wrote the first draft. All the authors contributed to the interpretation of data and completing and approving the final manuscript.

\section{Conflict of Interest}

The authors declare that they have no conflict of interest concerning this paper.

\section{References}

[1] Tiihonen J, Halonen P, Wahlbeck K et al. Topiramate add-on in treatment-resistant schizophrenia: A randomized, double-blind, placebo-controlled, crossover trial. J Clin Psychiatry 2005; 66: 1012-1015

[2] Kane JM, Correll CU. Past and present progress in the pharmacologic treatment of schizophrenia. J Clin Psychiatry 2010; 71: 1115-1124
[3] Carbon M, Correll CU. Clinical predictors of therapeutic response to antipsychotics in schizophrenia. Dialogues Clin Neurosci 2014; 16: 505-524

[4] Muscatello MR, Bruno A, De Fazio P et al. Augmentation strategies in partial responder and/or treatment-resistant schizophrenia patients treated with clozapine. Expert Opin Pharmacother 2014; 15: 2329-2345

[5] Wolff-Menzler C, Hasan A, Malchow B et al. Combination therapy in the treatment of schizophrenia. Pharmacopsychiatry 2010; 43: 122-129

[6] Nelson JC. Combined treatment strategies in psychiatry. J Clin Psychiatry 1993; 54: Suppl 42-49

[7] Veerman SRT, Schulte PF], de Haan L. Treatment for negative symptoms in schizophrenia: A comprehensive review. Drugs 2017; 77: 1423-1459

[8] Hartmann-Riemer MN, Hager OM, Kirschner M et al. The association of neurocognitive impairment with diminished expression and apathy in schizophrenia. Schizophr Res 2015; 169: 427-432

[9] Cohen AS, Saperstein AM, Gold JM et al. Neuropsychology of the deficit syndrome: New data and meta-analysis of findings to date. Schizophr Bull 2007; 33: 1201-1212

[10] Singh SP, Singh V, Kar N et al. Efficacy of antidepressants in treating the negative symptoms of chronic schizophrenia: Meta-analysis. $\mathrm{Br}$ ] Psychiatry 2010; 197: 174-179

[11] Correll CU, Sikich L, Reeves G et al. Metformin for antipsychotic-related weight gain and metabolic abnormalities: When, for whom, and for how long? Am J Psychiatry 2013; 170: 947-952

[12] Maayan L, Vakhrusheva J, Correll CU. Effectiveness of medications used to attenuate antipsychotic-related weight gain and metabolic abnormalities: A systematic review and meta-analysis. Neuropsychopharmacology 2010; 35: 1520-1530

[13] Zheng W, Li XB, Tang YL et al. Metformin for weight gain and metabolic abnormalities associated with antipsychotic treatment: meta-analysis of randomized placebo-controlled trials. J Clin Psychopharmacol 2015; 35: 499-509

[14] Wu RR, Zhang FY, Gao KM et al. Metformin treatment of antipsychoticinduced dyslipidemia: An analysis of two randomized, placebo-controlled trials. Mol Psychiatry 2016; 21: 1537-1544

[15] Liu Z, Zheng W, Gao S et al. Metformin for treatment of clozapineinduced weight gain in adult patients with schizophrenia: A metaanalysis. Shanghai Arch Psychiatry 2015; 27: 331-340

[16] Wu RR, Zhao JP, Jin $\mathrm{H}$ et al. Lifestyle intervention and metformin for treatment of antipsychotic-induced weight gain: A randomized controlled trial. JAMA 2008; 299: 185-193

[17] Mizuno Y, Suzuki T, Nakagawa A et al. Pharmacological strategies to counteract antipsychotic-induced weight gain and metabolic adverse effects in schizophrenia: A systematic review and meta-analysis. Schizophr Bull 2014; 40: 1385-1403

[18] Poyurovsky M, Isaacs I, Fuchs C et al. Attenuation of olanzapineinduced weight gain with reboxetine in patients with schizophrenia: A double-blind, placebo-controlled study. Am J Psychiatry 2003; 160: 297-302

[19] Czobor P, Volavka J, Sheitman B et al. Antipsychotic-induced weight gain and therapeutic response: A differential association. J Clin Psychopharmacol 2002; 22: 244-251

[20] Correll CU, Ng-Mak DS, Stafkey-Mailey D et al. Cardiometabolic comorbidities, readmission, and costs in schizophrenia and bipolar disorder: A real-world analysis. Ann Gen Psychiatry 2017; 16: 9

[21] Correll CU, Solmi M, Veronese $\mathrm{N}$ et al. Prevalence, incidence and mortality from cardiovascular disease in patients with pooled and specific severe mental illness: A large-scale meta-analysis of 3211768 patients and 113,383,368 controls. World Psychiatry 2017; 16: 163-180 
[22] Poyurovsky M, Fuchs C, Pashinian A et al. Attenuating effect of reboxetine on appetite and weight gain in olanzapine-treated schizophrenia patients: A double-blind placebo-controlled study. Psychopharmacology (Berl) 2007; 192: 441-448

[23] Eyding D, Lelgemann M, Grouven U et al. Reboxetine for acute treatment of major depression: Systematic review and meta-analysis of published and unpublished placebo and selective serotonin reuptake inhibitor controlled trials. BMJ (Clinical research ed) 2010; 341: c4737

[24] Cipriani A, Furukawa TA, Salanti G et al. Comparative efficacy and acceptability of 21 antidepressant drugs for the acute treatment of adults with major depressive disorder: A systematic review and network meta-analysis. Lancet 2018; 391: 1357-1366

[25] Li XP, Wang ZM, Zhao SX et al. Effect of reboxetine combined with clozapine on negative symptoms quality of life of the patients with schizophrenia. China Journal of Health Psychology 2008; 16: 133-135

[26] Sun J, Liu Y, Wang HX et al. Effect of Reboxetine combined with Haloperidol in the treatment of first-episode schizophrenia on cognition function. China Practical Medical 2011; 06: 4-6

[27] Zhao SX, Li ZS, Gen HS et al. Double-blind, placebo-controlled study of adjunctive reboxetine for metabolic syndrome induced by clozapine in patients with schizophrenia. Hebei Medical Journal 2013; v 35 : 3226-3228

[28] Shafti SS, Jafarabad MS, Azizi R. Tackling negative symptoms in male patients with schizophrenia using a norepinephrine reuptake inhibitor. Available at http://onlinelibrary.wiley.com/o/cochrane/clcentral/ articles/772/CN-01128772/frame.html

[29] Usall J, Lopez-Carrilero R, Iniesta R et al. Double-blind, placebo-controlled study of the efficacy of reboxetine and citalopram as adjuncts to atypical antipsychotics for negative symptoms of schizophrenia. J Clin Psychiatry 2014; 75: 608-615

[30] Hinkelmann K, Yassouridis A, Kellner M et al. No effects of antidepressants on negative symptoms in schizophrenia. J Clin Psychopharmacol 2013; 33: 686-690

[31] Matthews PRL, Horder ], Pearce M. Selective noradrenaline reuptake inhibitors for schizophrenia. Cochrane Database Syst Rev 2018; 1: CD010219

[32] Helfer B, Samara MT, Huhn M et al. Efficacy and safety of antidepressants added to antipsychotics for schizophrenia: A systematic review and meta-analysis. Am J Psychiatry 2016; 173: 876-886

[33] Kishi T, Mukai T, Matsuda Y et al. Efficacy and safety of noradrenalin reuptake inhibitor augmentation therapy for schizophrenia: $\mathrm{A}$ meta-analysis of double-blind randomized placebo-controlled trials. J Psychiatr Res 2013; 47: 1557-1563

[34] Choi Y]. Efficacy of adjunctive treatments added to olanzapine or clozapine for weight control in patients with schizophrenia: A systematic review and meta-analysis. Scientific World Journal 2015; 2015: 970730

[35] Yu JN, Chai M. [Treatment of negative symptoms of schizophrenia: A controlled study]. jilin Medical Journal. 2012; 33: 4988-4989

[36] Leucht S, Komossa K, Rummel-Kluge C et al. A meta-analysis of head-to-head comparisons of second-generation antipsychotics in the treatment of schizophrenia. Am J Psychiatry 2009; 166: 152-163
[37] Amrami-Weizman A, Maayan R, Gil-Ad I et al. The effect of reboxetine co-administration with olanzapine on metabolic and endocrine profile in schizophrenia patients. Psychopharmacology 2013; 230: 23-27

[38] Kay SR, Fiszbein A, Opler LA. The positive and negative syndrome scale (PANSS) for schizophrenia. Schizophr Bull 1987; 13: 261-276

[39] Overall JE, Gorham DR. The Brief Psychiatric Rating-Scale. Psychol Rep 1962; 10: 799-812

[40] Andreasen NC. Scale for the Assessment of Negative Symptoms (SANS). IA: University of lowa; lowa City: 1983

[41] Andreasen NC. Scale for the Assessment of Positive Symptoms (SAPS). IA: University of lowa; lowa City: 1984

[42] Moher D, Liberati A, Tetzlaff J et al. Preferred reporting items for systematic reviews and meta-analyses: The PRISMA statement. Ann Intern Med 2009; 151: 264-269

[43] DerSimonian R, Laird N. Meta-analysis in clinical trials. Control Clin Trials 1986; 7: 177-188

[44] Egger M, Davey Smith G, Schneider M et al. Bias in meta-analysis detected by a simple, graphical test. BMJ 1997; 315: 629-634

[45] Higgins J, Higgins J. Cochrane Handbook for Systematic Reviews of Interventions. Hoboken: John Wiley \& Sons; 2008

[46] Balshem $\mathrm{H}$, Helfand M, Schunemann $\mathrm{H}$ ] et al. GRADE guidelines: 3. Rating the quality of evidence. J Clin Epidemiol 2011; 64: 401-406

[47] Atkins D, Best D, Briss PA et al. Grading quality of evidence and strength of recommendations. BMJ 2004; 328: 1490

[48] Zheng W, Cai DB, Zhang QE et al. Adjunctive ondansetron for schizophrenia: A systematic review and meta-analysis of randomized controlled trials. J Psychiatr Res 2019; 113: 27-33

[49] Jadad AR, Moore RA, Carroll D et al. Assessing the quality of reports of randomized clinical trials: Is blinding necessary? Control Clin Trials 1996; 17: 1-12

[50] Linde K, Clausius N, Ramirez G et al. Are the clinical effects of homeopathy placebo effects? A meta-analysis of placebo-controlled trials. Lancet 1997; 350: 834-843

[51] Schutz G, Berk M. Reboxetine add on therapy to haloperidol in the treatment of schizophrenia: A preliminary double-blind randomized placebo-controlled study. Int Clin Psychopharmacol 2001; 16: 275-278

[52] Sterne JA, Sutton AJ , Ioannidis JP et al. Recommendations for examining and interpreting funnel plot asymmetry in meta-analyses of randomised controlled trials. BMJ (Clinical research ed.) 2011; 343, d4002

[53] Mayer AF, Schroeder C, Heusser K et al. Influences of norepinephrine transporter function on the distribution of sympathetic activity in humans. Hypertension 2006; 48: 120-126

[54] Poyurovsky M, Fuchs C, Pashinian A et al. Reducing antipsychoticinduced weight gain in schizophrenia: A double-blind placebo-controlled study of reboxetine-betahistine combination. Psychopharmacology (Berl) 2013; 226: 615-622

[55] Ascher-Svanum H, Stensland M, Zhao Z et al. Acute weight gain, gender, and therapeutic response to antipsychotics in the treatment of patients with schizophrenia. BMC Psychiatry 2005; 5: 3 